\title{
CORRECTION
}

\section{Correction to: Bleeding and thrombotic events in adults supported with venovenous extracorporeal membrane oxygenation: an ELSO registry analysis}

Jose I. Nunez ${ }^{1}$, Andre F. Gosling ${ }^{2}$, Brian O'Gara ${ }^{3}$, Kevin F. Kennedy ${ }^{4}$, Peter Rycus ${ }^{5}$, Darryl Abrams ${ }^{6}$, Daniel Brodie ${ }^{6}$, Shahzad Shaefi ${ }^{3}$ A. Reshad Garan ${ }^{7}$ and E. Wilson Grandin ${ }^{4,7^{*}}$

@ 2022 Springer-Verlag GmbH Germany, part of Springer Nature

\section{Correction to: Intensive Care Med https://doi.org/10.1007/s00134-021- 06593-x}

Figures 2 has been published incorrect. Please find the correct Fig. 2 below.

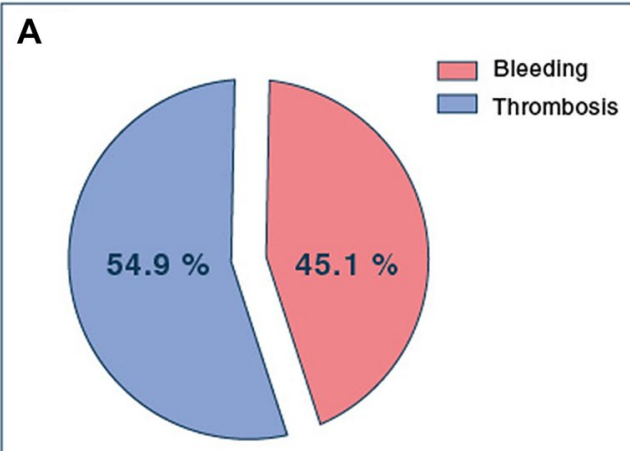

Total Events $=4840$
B

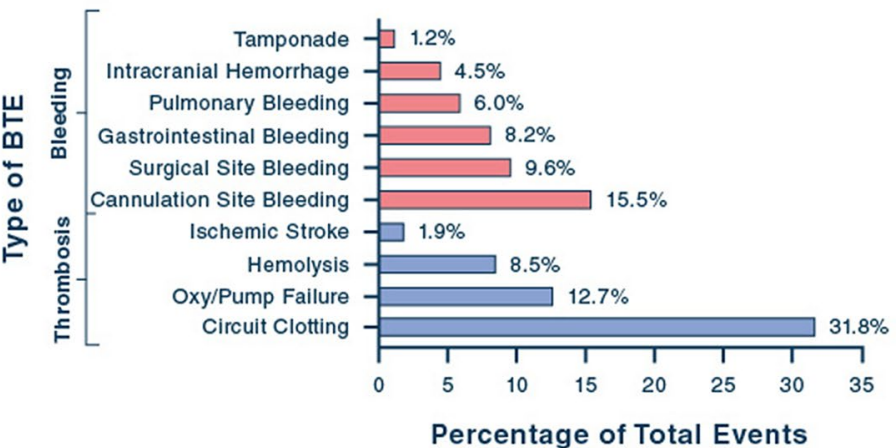

Fig. 2 Frequency of bleeding and thrombotic events during VV-ECMO. A Proportion of BTEs comprised of bleeding or thrombotic events. B Frequency of specific types of BTEs. BTEs, bleeding and thrombotic events; Oxy/pump failure, oxygenator/pump failure

*Correspondence: wgrandin@bidmc.harvard.edu

${ }^{7}$ Division of Cardiovascular Medicine, Section of Advanced Heart Failure,

Department of Medicine, Beth Israel Deaconess Medical Center, 185

Pilgrim Road, DE-319, Boston, MA 02215, USA

Full author information is available at the end of the article

The original article can be found online at https://doi.org/10.1007/ s00134-021-06593-x 


\section{Author details}

${ }^{1}$ Department of Medicine, Montefiore Medical Center, Albert Einstein College of Medicine, Bronx, NY, USA. ${ }^{2}$ Department of Anesthesiology, Duke University Hospital, Durham, NC, USA. ${ }^{3}$ Department of Anesthesia, Critical Care and Pain Medicine, Beth Israel Deaconess Medical Center, Boston, MA, USA. ${ }^{4}$ Smith

Center for Cardiology Outcomes Research, Beth Israel Deaconess Medical Center, Boston, MA, USA. ${ }^{5}$ Extracorporeal Life Support Organization, Ann

Arbor, MI, USA. ${ }^{6}$ Division of Pulmonary and Critical Care Medicine, Columbia Presbyterian Medical Center, New York, NY, USA. ${ }^{7}$ Division of Cardiovascular Medicine, Section of Advanced Heart Failure, Department of Medicine, Beth Israel Deaconess Medical Center, 185 Pilgrim Road, DE-319, Boston, MA 02215, USA.

\section{Publisher's Note}

Springer Nature remains neutral with regard to jurisdictional claims in published maps and institutional affiliations.

Published: 18 January 2022 